\title{
Editorial
}

\section{Is insulin atherogenic?}

\author{
R. J. Jarrett \\ Division of Community Medicine, United Medical and Dental Schools of Guy's and St. Thomas's Hospitals, London, UK.
}

\section{"Never fall in love with your hypothesis" P. B. Medawar (1915-1987)}

Stout [1] in a recent review of this topic stated that the principal evidence in favour of the view that insulin is atherogenic arises from epidemiological studies. The present review, therefore, is mainly devoted to a consideration of studies using epidemiological methods.

\section{Background}

In 1963 [2] Vallance-Owen and Ashton reported increased antagonism to insulin action associated with extracts of plasma albumin from patients following a myocardial infarction. Two years later two groups $[3,4]$ reported increased plasma insulin levels in survivors of myocardial infarcts. Subsequently there were several reports of increased insulin levels in patients with coronary [5, 6], cerebral [7] and peripheral [8] vascular disease. Thus, an association between hyperinsulinaemia and atherosclerosis was established, though, as Stout pointed out in an earlier review in this Journal [9], there were several discrepancies in the detailed results between the studies. Though several hypotheses could explain the association, that insulin might be causally related was suggested [9] by the fact that diabetic patients were at increased risk of atherosclerosis; and either were hyperinsulinaemic due to insulin therapy or, if Type 2 (non-insulin-dependent), due to associated obesity. Additional, circumstantial evidence was derived from experimental pathology [9].

\section{Prospective studies: non-diabetic subjects}

Three prospective studies have examined the relationship between baseline variables including insulin and subsequent morbidity and mortality. Two of these were confined to middle-aged male police $[10,11]$ and the third included both sexes in a community study [12].

\section{(1) The Helsinki policemen study}

Nine hundred eighty-two men aged 35-64 years were studied in 1971-72 and followed until 1980 [11]. They were free of coronary heart disease (CHD) at baseline as judged by no history or signs of CHD or no electrocardiographic evidence of definite myocardial infarction. Men with previously diagnosed diabetes were also excluded. Included in the baseline evaluation was an oral glucose tolerance test ( 75 or $90 \mathrm{~g}$ glucose depending on body surface area) with venous blood samples at 0,1 and $2 \mathrm{~h}$. During the $91 / 2$ year follow-up 26 men died from CHD and 37 men had a nonfatal myocardial infarction. The incidence of these combined end-points showed a positive non-linear relationship to both plasma insulin and glucose values at each time point. For plasma insulin, excess CHD events were largely concentrated in the top $10 \%$ of the distribution and in univariate analysis the association was significant only for the post-load values. In multiple logistic analyses the two post-load insulin variables were significantly and independently associated with the CHD end-points.

\section{(2) The Paris prospective study}

Seven thousand four hundred thirty-five men aged 43-54 years were studied in 1968-73. Excluded from this total were men with CHD, those on drugs for diabetes or hypertension and those with missing insulin or glucose values, leaving 6439 men in the follow-up at 5 years [10], though this somehow increased to 7038 at 11 years [13], apparently because known diabetic patients and treated hypertensive patients were reinstated. At baseline plasma insulin and glucose were measured fasting and $2 \mathrm{~h}$ after a $75 \mathrm{~g}$ oral glucose load. CHD 
mortality data up to 11 years of follow-up have been published [13]. In univariate analysis, excess CHD mortality tended to concentrate in the upper quintile of the distribution of both glucose and insulin distributions, fasting and $2 \mathrm{~h}$ after the glucose load. For multivariate analysis the Cox regression model was used and only the fasting insulin value was significantly and independently predictive of CHD mortality. However, statistical modelling for multiple variables is not without problems of interpretation [14]. Thus, in another report from the Paris Prospective Study [15] examining the roles of obesity and hypertension, the cardiovascular death rate was compared across quintiles of body mass index (BMI) in hypertensive (diastolic blood pressure $>95 \mathrm{mmHg}$ ) and non-hypertensive men. The relative rates declined with increasing BMI, i.e. hypertension had the most effect in thin men, a phenomenon which could not have been observed using conventional multivariate or multiple logistic analyses. In the present context it is worth noting the well attested positive association between BMI and plasma insulin.

\section{(3) The Busselton study}

In 1966,3390 adults, representing $91 \%$ of the population of Busselton Shire, attended for mass health examinations between 08.00 and 20.00 hours. Blood samples were collected $1 \mathrm{~h}$ after a $50 \mathrm{~g}$ oral glucose load, without reference to previous food intake. The prevalence of CHD (history and/or ECG) was not significantly related to the $1 \mathrm{~h}$ serum insulin level in univariate analyses [12]. The 6 year incidence of CHD (fatal and non-fatal) was examined in three age groups - 40-59, 60-69, 70+ years. For the $1 \mathrm{~h}$ plasma insulin, the only significant association occurred in men aged 60-69 years. Twelve year mortality from CHD was similarly analysed and again the only significant, univariate correlation occurred in men aged 60-69 years. By contrast, in women only the $1 \mathrm{~h}$ blood glucose value was significantly related to CHD mortality. A subsequent analysis was confined to the 13 -year mortality data in subjects aged 40-74 years at entry and also apparently free of CHD [16]. For this analysis two age groups - 40-59 years and 60-74 years - were considered separately by sex. Mortality was considered as all causes, or due to cardiovascular disease, CHD, or cancer, respectively. In multiple regression analyses, in the age group $40-59$ years, serum insulin was not a significant predictor of mortality in either sex, with the exception of a negative association with all mortality causes in men. In the age group 60-74 years, serum insulin was significantly and positively related to allcauses mortality in men, but this was apparently due to cancer mortality specifically.

Thus, the three prospective studies are inconsistent. In the Helsinki study post-load insulin values, and in the Paris Prospective Study fasting insulin values, were predictive of $\mathrm{CHD}$ in multivariate analyses, assuming the validity of the statistical modelling. However, in the Busselton study, multivariate analysis removed any association between postload insulin level and CHD mortality, which in any case was confined to men in one age group in univariate analysis. Furthermore, all three studies lack measurement of a potentially confounding variable, HDL cholesterol, a consistent (though not invariable [17]) predictor of CHD and consistently associated, inversely, with plasma insulin [18-22].

\section{Studies in subjects with diabetes or glucose intolerance}

In the Bedford Study subjects with glucose intolerance ('borderline diabetes') had a single measurement of plasma insulin performed on a $2 \mathrm{~h}$ post-load blood sample. After 10 years of follow-up [23] neither CHD morbidity nor mortality were significantly related to baseline insulin levels, which tended to be lower in those with a CHD event.

In the Schwabing Study [24], three groups were examined - Type 2 diabetic patients treated with or without insulin and a non-diabetic control group. CHD was identified by electrocardiography and C-peptide measured on a fasting blood sample. In each of the three groups there was a significantly positive (though non-linear) association between the proportion of subjects with CHD and quintiles of C-peptide distribution. The insulin treated diabetic patients had the highest prevalence of CHD but the lowest average fasting $\mathrm{C}$-peptide. However, in these patients the dose of insulin and fasting free insulin levels in those with macrovascular disease (CHD and/or abnormal ultrasonic tests of carotid or peripheral vessels) were significantly higher than in those classified as normal. In a 5-year follow-up of these patients, in univariate analyses insulin dose was a significant predictor of stroke/myocardial infarction/foot gangrene combined, and of asymptomatic peripheral vascular disease [24].

Hockaday has presented a preliminary analysis of a 10-year follow-up of a group of Type 2 diabetic patients [25]. The ratio of fasting plasma insulin/BMI was significantly higher at baseline in those with electrocardiographic abnormalities and almost significantly higher in those with normal ECGs at baseline and abnormal ECGs at 10 years. However, measures of baseline plasma insulin were unrelated to 10 year mortality.

In the University Group Diabetes Program subjects with Type 2 diabetes were randomly allocated to several treatment groups. Mortality and morbidity were reported for 13 years of follow-up in the 2 insulin-treated groups (insulin standard and insulin variable) compared with the placebo treated group [26]. There were substantial differences in blood glucose values between the 3 groups, with lowest values in the insulin variable group, but only trivial and non-significant dif- 
ferences in the incidence of cardiovascular morbidity and mortality and in all mortality causes.

A Finnish study [28] compared 133 newly diagnosed patients with Type 2 diabetes and a randomly selected non-diabetic control group. The prevalence of CHD (symptoms and/or ECG abnormalities) was more than 3-fold greater in the diabetic group. In the female diabetic patients fasting and post load plasma insulin levels were significantly higher in those with CHD but no differences were observed in the male diabetic patients. After 5 years, according to a preliminary report [27], there was no relationship between baseline plasma insulin levels and the incidence of CHD death/non fatal myocardial infarction. In another preliminary analysis of two groups of patients with Type 2 diabetes from East and West Finland, respectively [27], fasting plasma insulin was associated with a verified definite or possible myocardial infarction in diabetic patients of both sexes, independently of other risk factors, but was not so associated in nondiabetic control subjects.

In Type 1 (insulin-dependent) diabetic patients the risk of CHD was substantially increased in those developing proteinuria [29]. It is not yet known whether the risk of CHD is increased in patients with Type 1 diabetes whose renal function is unimpaired.

Mexican Americans [30], Amerindians [31, 32] and Nauruans [33] share a high risk of Type 2 diabetes and also are hyperinsulinaemic before glucose intolerance occurs. In one of these populations - the Pima Indians - the prevalence of CHD and post-mortem evidence of coronary disease was shown to be low compared with white Americans [34]. Furthermore, in male Pima diabetic patients, all causes mortality rates were not different from those in non-diabetic subjects; they were higher in female diabetic patients, but only in the less obese, who might be expected to be also less hyperinsulinaemic [35].

\section{Comment}

It is hardly necessary to point out that the studies whether cross-sectional or prospective - in diabetic patients or non-diabetic subjects, of the relationship between hyperinsulinaemia and (mainly) $\mathrm{CHD}$, lack consistency, an important attribute if causality is to be entertained. Indeed, in a court of law the verdict on insulin would have to be 'non proven'. However, there is sufficient circumstantial evidence to warrant some enquiry into the possible reasons for such inconsistency in findings, with potential outcome in the design of future studies, if not in the interpretation of existing studies.

(1) Hyperinsulinaemia. The term is loosely used to include high fasting levels of plasma insulin (or of Cpeptide), high levels in response to a glucose stimulus and high levels of free insulin in insulin-treated diabetic patients. While it may be reasonable to assume that individuals with high fasting levels are also more exposed to insulin action, it is not necessarily true of individuals with excessive responses to the somewhat unusual stimulus of an oral glucose load. The hyperinsulinaemia of insulin treatment is under-researched, but the evidence from the only random allocation study [26] is that 13 years of insulin treatment in subjects with Type 2 diabetes does not affect morbidity or mortality. If true, then this must cast doubt upon the interpretation of experimental studies such as those which demonstrate effects of insulin upon cells of the arterial wall [36]; for the insulin-treated subjects in the University Group Diabetes Program (UGDP) study would have been subject to long periods of peripheral hyperinsulinaemia. The innocuous effect of insulin therapy per se demonstrated in the UGDP study receives some indirect support from the study of patients with Type 1 diabetes in Denmark [29] where CHD predominated in subjects with proteinuria. It would be of considerable interest to mount a prospective study comparing the incidence of CHD in Type 1 diabetes with that in a control population taking into consideration not only clinical proteinuria but also microalbuminuria, which is also related to elevated blood pressure levels in patients with Type 1 diabetes [37].

(2) Confounding variables. A considerable - perhaps insurmountable - problem in the interpretation of both clinical and epidemiological studies arises from the associations between levels of insulin and a number of other variables also implicated in the genesis of atherosclerosis and/or cardiovascular disease. These include obesity and fat distribution [38], blood pressure [8, 28, 39], HDL cholesterol [18-22], plasma triglyceride [5, 40], sex hormones [41], exercise/activity [42] and diet [43]. It is beyond the scope of this review to comment further upon the complex metabolic factors underlying these associations. However, given these complexities, it seems unlikely that statistical modelling will prove enlightening even if a given study managed to measure all the relevant variables. There is an obvious need for exploratory metabolic studies.

(3) Insulin resistance. Modan et al. [44] stated that "insulin resistance, hyperinsulinaemia and glucose intolerance are practically synonymous". However, insulin resistance is an omnibus term and when used, requires definition. In many studies it is inferred rather than measured, and high insulin levels do not necessarily indicate increased insulin secretion rates $[45,46]$. However defined, it is most commonly associated with obesity, in particular abdominal obesity [38]. While obesity is an undoubted factor in the genesis of Type 2 diabetes, its role in atherosclerosis is less certain. Thus Barrett-Connor [47], who reviewed the literature for the NIH Consensus Development Conference on Obesity, 
concluded "despite its plausibility, the hypothesis that obesity causes atherosclerosis could not be supported". I would be slightly less categorical about hyperinsulinaemia/insulin resistance, but conclude that the hypothesis that they cause atherosclerosis requires more substantial observational and experimental evidence before it can be supported.

\section{References}

1. Stout RW (1987) Insulin and atheroma - an update. Lancet I: 1077-1079

2. Vallance-Owen J, Ashton WL (1963) Cardiac infarction and insulin antagonism. Lancet I: 1226-1228

3. Peters N, Hales CN (1965) Plasma-insulin concentrations after myocardial infarction. Lancet I: 1144-1145

4. Nikkila EA, Miettinen TA, Vessene MR, Pelkonen R (1965) Plasma-insulin in coronary heart disease: response to oral and intravenous glucose and to tolbutamide. Lancet II: $508-511$

5. Tzagournis M, Chiles R, Ryan JM, Skillman TG (1968) Interrelationships of hyperinsulinism and hypertriglyceridemia in young patients in coronary heart disease. Circulation 38: 1156-1163

6. Malherbe C, de Gasparo M, Berthet P, de Hertogh R, Hoet JJ (1970) The pattern of plasma insulin responses to glucose in patients with a previous myocardial infarction - the respective effects of age and disease. Eur J Clin Invest 1: 265-270

7. Gertler MM, Leetma HE, Saluste E, Covalt DA, Rosenberger JL (1972) Covert diabetes mellitus in ischaemic heart and cerebrovascular disease. Geriatrics 27: 105-120

8. Welborn TA, Breckenridge A, Rubinstein AH, Dollery CT, Russell Fraser T (1966) Serum-insulin in essential hypertension and in peripheral vascular disease. Lancet I: 1336-1337

9. Stout RW (1979) Diabetes and atherosclerosis - the role of insulin. Diabetologia 16: 141-50

10. Ducimetiere P, Eschwege E, Richard J, Rosselin G, Claude JR (1982) Clinical complications of coronary heart disease according to plasma insulin and glucose levels. A further analysis of the Paris Prospective Study. In: Eschwege E (ed) Advances in diabetes epidemiology, INSERM Symposium No.22. Elsevier, Amsterdam, pp 149-155

11. Pyörälä K, Savolainen E, Kaukola S, Haapakoski J (1982) High plasma insulin as a coronary heart disease risk factor. In: Eschwege E (ed) Advances in diabetes epidemiology, INSERM Symposium No. 22. Elsevier, Amsterdam, pp 143-148

12. Welborn TA, Wearne K (1979) Coronary heart disease incidence and cardiovascular mortality in Busselton with reference to glucose and insulin concentration. Diabetes Care 2: 154-160

13. Eschwege E, Richard JL, Thibult N, Ducimetiere P, Warnet JM, Claude JR, Rosselin GE (1985) Coronary heart disease mortality in relation with diabetes, blood glucose and plasma insulin levels: the Paris Prospective study, ten years later. Horm Metab Res [Suppl 15]: 41-46

14. Vandenbroucke JP (1987) Should we abandon statistical modelling altogether? Am J Epidemiol 126: 10-13

15. Cambien F, Chretien JM, Ducimetiere P, Guize L, Richard JL (1985) Is the relationship between blood pressure and cardiovascular risk dependent on body mass index? Am J Epidemiol 122: 434-442

16. Cullen K, Stenhouse NS, Wearne KL, Welborn TA (1983) Multiple regression analysis of risk factors for cardiovascular disease and cancer mortality in Busselton, Western Australia - 13 year study. J Chronic Dis 36: 371-377

17. Pocock SJ, Shaper AG, Phillips AN, Walker M, Whitehead TP (1986) High density lipoprotein cholesterol is not a major risk factor for ischaemic heart disease in British men. Br Med J 292: 515-519
18. Stalder M, Pometta D, Suenram A (1981) Relationship between plasma insulin levels and high density lipoprotein cholesterol levels in healthy men. Diabetologia 21: 544-548

19. Garcia-Webb P, Bonser AM, Whiting D, Masarei JRL (1983) Insulin resistance - a risk factor for coronary heart disease? Scand J Clin Lab Invest 43: 677-685

20. Laakso M, Pyörälä K, Voutilainen E, Marniemi J (1987) Plasma insulin and serum lipids and lipoproteins in middle-aged non-insulin-dependent diabetic and non-diabetic subjects. Am J Epidemiol 125: 611-621

21. Hornick CA, Fellmeth BD (1981) High density lipoprotein cholesterol, insulin and obesity in Samoans. Atherosclerosis 39: 321-328

22. Burke GL, Webber LS, Stinavasan SR, Radhakrishamurthy B, Freedman DS, Berenson GS (1986) Fasting plasma glucose and insulin levels and their relationship to cardiovascular risk factors in children: Bogalusa heart study. Metabolism 35: 441-446

23. Jarrett RJ, McCartney P, Keen H (1982) The Bedford survey. Ten year mortality rates in newly diagnosed diabetics and normoglycaemic controls and risk indices for coronary heart disease in borderline diabetics. Diabetologia 22: 79-84

24. Janka HU, Ziegler AG, Standl E, Mehnert H (1987) Daily insulin dose as a predictor of macrovascular disease in insulin treated non-insulin-dependent diabetics. Diab Metab 13: 359-364

25. Hockaday TDR (1987) Serum insulin concentrations and anticipatory factors of cardiomyopathy in NIDDM. Diab Metab 13: 354-358

26. Knatterud GL, Klimt CR, Levin ME, Jacobson ME, Goldner MG (1978) Effects of hypoglycemic agents on vascular complications in patients with adult-onset diabetes VII. Mortality and selected nonfatal events with insulin treatment. JAMA 240: $37-42$

27. Pyörälä K, Uusitupa M, Laakso M, Siitonen O, Niskanen L, Rönnemaa T (1987) Macrovascular complications in relation to hyperinsulinaemia in non-insulin-dependent diabetes mellitus. Diab Metab 13: 345-349

28. Uusitupa M, Siitonen O, Pyörälä K, Mustonen J, Voutilainen E, Hersio K, Pentila I (1987) Relationship of blood pressure and left ventricular mass to serum insulin levels in newly diagnosed non-insulin-dependent (Type 2) diabetic patients and in non-diabetic subjects. Diabetes Res 4: 19-25

29. Jensen T, Borch Johnsen K, Kofoed-Enevoldsen A, Deckert $T$ (1987) Coronary heart disease in young Type 1 (insulin-dependent) diabetic patients with and without diabetic nephropathy: incidence and risk factors. Diabetologia 30: 144-148

30. Haffner SM (1987) Hyperinsulinaemia as a possible etiology for the high prevalence of non insulin dependent diabetes in Mexican Americans. Diab Metab 13: 337-344

31. Aronoff SL, Bennett PH, Gordon P, Rushforth N, Miller M (1977) Unexplained hyperinsulinaemia in normal and "prediabetic" Pima Indians compared with normal Caucasians. An example of racial differences in insulin secretion. Diabetes 26: $827-840$

32. Frohman LA, Doeblin TD, Emerling FG (1969) Diabetes in the Seneca Indians. Plasma insulin responses to oral carbohydrate. Diabetes 18: 38-43

33. Sicree RA, Zimmet P, King HOM, Coventry JS (1987) Plasma insulin response among Nauruans: prediction of deterioration in glucose tolerance over 6 yr. Diabetes 36: 179-186

34. Ingelfinger JA, Bennett PH, Liebow IM, Miller M (1976) Coronary heart disease in the Pima Indians: electrocardiographic findings and post mortem evidence of myocardial infarction in a population with a high prevalence of diabetes mellitus. Diabetes 25: 561-565

35. Pettitt DJ, Lisse JR, Knowler WC, Bennett PH (1982) Mortality as a function of obesity and diabetes mellitus. Am $\mathbf{J}$ Epidemiol 115: 359-366

36. Young IR, Stout RW (1987) Effects of insulin and glucose on the cells of the arterial wall: interaction of insulin with dibutyryl cyclic AMP and low density lipoprotein in arterial cells. Diab Metab 13: 301-306 
37. Wiseman M, Viberti G, Mackintosh D, Jarrett RJ, Keen H (1984) Glycaemia, arterial pressure and microalbuminuria in Type 1 (insulin-dependent) diabetes mellitus. Diabetologia 26: 401-405

38. Björntorp P (1987) Adipose tissue distribution, plasma insulin, and cardiovascular disease. Diab Metab 13: 381-385

39. Florey C du V, Uppal S, Lowy C (1976) Relation between blood pressure, weight, and plasma sugar and serum insulin levels in school children aged 9-12 years in Westland, Holland. Br Med J 1: $1368-1371$

40. Uusitupa M, Siitonen O, Voutilainen E, Aro A, Hersio K, Pyörälä K, Penttila I, Ehnholm C (1986) Serum lipids and lipoproteins in newly diagnosed non-insulin-dependent (Type II) diabetic patients, with special reference to factors influencing HDL-cholesterol and triglyceride levels. Diabetes Care 9: 17-22

41. Lichenstein MJ, Yarnell JWG, Elwood PC, Beswick AD, Sweetnam PM, Marks V, Teale D, Riad-Fahmy D (1987) Sex hormones, insulin, lipids, and prevalent ischemic heart disease. Am J Epidemiol 126: 647-657

42. Björntorp P, de Jounge K, Sjöstrom L, Sullivan L (1970) The effect of physical training on insulin production in obesity. Metabolism 19: 631-638

43. Thomas BJ, Jarrett RJ, Keen H, Ruskin HJ (1982) Relation of habitual diet to fasting plasma insulin concentration and the insulin response to oral glucose. Hum Nutr Clin Nutr 36C: 49-56
44. Modan M, Halkin H, Fuchs Z, Lusky A, Chetrit A, Segal P, Eshkol A, Almog S, Shefi M (1987) Hyperinsulinaemia - a link between glucose intolerance, obesity, hypertension, dyslipoproteinemia, elevated serum uric acid and internal cation imbalance. Diab Metab 13: 375-380

45. Faber OK, Christensen K, Kehlet H, Madsbad S, Binder C (1981) Decreased insulin removal contributes to hyperinsulinaemia in obesity. J Clin Endocrinol 53: 618-621

46. Bonora E, Coscelli C, Butturini U (1986) Insulin metabolism is a major factor responsible for high or low peripheral insulin levels in response to oral glucose loading in the healthy man. Ann Nutr Metab 30: 219-226

47. Barrett-Connor E (1985) Obesity, atherosclerosis, and coronary artery disease. Ann Int Med 106: 1010-1019

Dr. R.J.Jarrett

Division of Community Medicine

United Medical and Dental Schools of Guy's and

St. Thomas's Hospitals (Guy's Campus)

London, SE1 9RT

UK 